\title{
APLIKASI FEEDBACK HARVEST CONTROL RULE SEBAGAI ALTERNATIF ATURAN KENDALI TANGKAP PERIKANAN LAYANG (Decapterus sp) DI PRIGI, TRENGGALEK
}

\author{
Ledhyane Ika Harlyan $^{\mathrm{a}, *}$, Wahida Kartika Sari ${ }^{\mathrm{a}}$, Darmawan Ockto Sutjipto ${ }^{\mathrm{a}}$, Wakhit Rhomadona ${ }^{\mathrm{b}}$, \\ Muhammad Arif Rahman ${ }^{a}$ \\ aFakultas Perikanan dan Ilmu Kelautan, Jalan Veteran, Malang, Indonesia \\ ${ }^{\mathrm{b}}$ Pelabuhan Perikanan Nusantara Prigi, Jalan Tasik Madu, Gares Kidul, Prigi, Watulimo, Trenggalek, \\ Indonesia \\ *Koresponden penulis: ledhyane@ub.ac.id
}

\begin{abstract}
Abstrak
Perikanan layang yang didaratkan di Pelabuhan Perikanan Nusantara (PPN) Prigi merupakan perikanan pelagis yang disusun oleh tiga spesies sumber daya ikan layang yaitu layang anggur (Decapterus kuroides), layang benggol (Decapterus ruselli) dan layang deles (Decapterus macrosoma). Aturan kendali tangkap pada perikanan layang kerap menggunakan model konvensional spesies tunggal, meski secara teknis tidak sesuai digunakan pada perikanan layang tercampur yang disusun oleh lebih dari satu spesies (multispesies). Aplikasi feedback harvest control rule (HCR) merupakan alternatif aturan kendali tangkap yang tervalidasi yang dapat digunakan untuk perikanan multispesies. Oleh karena itu, tujuan penelitian ini adalah untuk memperoleh perbandingan teknis aplikasi feedback HRC dan model konvensional surplus produksi sehingga dapat digunakan sebagai rujukan pada pengelolaan perikanan layang di perairan Prigi. Pada penelitian ini dilakukan estimasi jumlah tangkapan yang diperbolehkan (allowable biological catch/ABC $\mathrm{A}_{\mathrm{y}}$ ) dengan menggunakan dua aturan kendali tangkap yaitu feedback HCR dan model konvensional surplus produksi Schaefer (1954) dengan menggunakan data hasil tangkapan dan upaya penangkapan (trip) dalam kurun waktu 2011 - 2020. Hasil estimasi model Schaefer (1954) menunjukkan $\mathrm{ABC}_{\mathrm{y}}$ bahwa hanya dapat diestimasi untuk layang anggur, sementara dua spesies layang lainnya, tidak memenuhi asumsi model Schaefer (1954). Penggunaan aplikasi feedback HCR pada ketiga spesies layang lebih praktis karena mampu mengestimasi $\mathrm{ABC}_{\mathrm{y}}$ tanpa perlu dilakukan pemisahan data hasil tangkapan dan upaya penangkapan berdasarkan spesies.
\end{abstract}

Kata kunci: model surplus produksi, perikanan data tercampur, perikanan multispesies, pendekatan spesies tunggal

\begin{abstract}
Scad fishery that landed in Prigi fishing port comprised by three scads species, Redtail scad (Decapterus kuroides), Indian scad (Decapterus ruselli) and Shortfin scad (Decapterus macrosoma). Scad fisheries management largely use conventional single-species approach, though technically it is not applicable to employ in such mixed-species data that composed from multispecies fishery. Feedback harvest control rule (HCR) is an alternative validated fishing strategy that can be applied for multispecies fishery. The aim of this study was to obtain technical comparison of feedback HCR and conventional surplus production model, Schaefer model (1954) to manage scads fishery in Prigi. In this study, the allowable biological catch $\left(A B C_{y}\right)$ was estimated by applying two HCRs, feedback HCR application and a surplus production model, Schaefer Model (1954) into catch and effort of Scads fisheries data series of 2011 - 2020. The estimation of Schaefer (1954) conventional model showed that the estimation of $\mathrm{ABC}_{\mathrm{y}}$ can be conducted only for Redtail scads, since the condition of the other two species could not meet the Schaefer model assumptions. Compared to the surplus production model, the use of feedback HCR for three Scads is more practical since it can provide $\mathrm{ABC}_{\mathrm{y}}$ without species separation in catch and effort data.
\end{abstract}

Keywords: mixed-species data, multispecies fishery, single-species approach, surplus production model 


\section{PENDAHULUAN}

Perikanan layang merupakan perikanan pelagis dengan eksploitasi relatif tinggi mengingat tingginya permintaan pasar lokal maupun ekspor. Salah satu sumber daya ikan pelagis dengan tingkat eksploitasi relatif tinggi adalah ikan layang. Sumberdaya ikan layang yang didaratkan di PPN Prigi disusun oleh tiga spesies layang yaitu: layang anggur (Decapterus kuroides), layang benggol (Decapterus ruselli) dan layang deles (Decapterus macrosoma). Meski demikian dalam pencatatan data statistik perikanan maupun perhitungan estimasi sumberdaya kerap terjadi agregasi spesies [1].

Agregasi spesies umum terjadi pada perikanan multispesies dimana terjadi keterbatasan waktu dan tenaga dalam pemisahan spesies [2]-[4] yang mengakibatkan hanya tersedianya data perikanan yang tercampur (mixed-species data). Informasi spesifik mengenai spesies yang didaratkan tidak mampu diperoleh dan digantikan dengan informasi mengenai grup spesies didasarkan pada nama genus atau famili [2], [4].

Pengelolaan perikanan multispesies layang yang didaratkan di PPN Prigi telah didokumentasikan dalam 10 tahun terakhir meliputi pengkajian terhadap tingkat pemanfaatan, status stok serta musim penangkapan tetap dilakukan berkala [5]-[9]. Hal tersebut dilakukan untuk menjaga kelangsungan perikanan pelagis khususnya perikanan yang lestari [10].

Pada beberapa dokumentasi penelitian dan rekomendasi pengelolaan sumberdaya ikan yang layang, pengkajian stok dan penetapan jumlah tangkapan yang diperbolehkan (JTB) dilakukan dengan menggunakan pendekatan konvensional spesies tunggal, baik dengan model Schaefer (1954) maupun model Fox (1970). Pendekatan surplus produksi konvensional spesies tunggal didefinisikan sebagai pendekatan kajian stok yang dilakukan pada perikanan dengan asumsi terdapat satu alat tangkap yang menangkap satu spesies [11], [12].

Secara teknis, perikanan multispesies yang hanya mampu menyediakan data spesies ercampur seharusnya dikaji dengan pendekatan yang memungkinkan penggunaan data spesies tercampur [10], [12]-[14]. Oleh karena itu diperlukan aplikasi pengkajian stok dan penentuan tingkat eksploitasi yang dapat digunakan pada data spesies tercampur yang umumnya terjadi pada perikanan multispesies.

Aplikasi feedback harvest control rule (feedback HCR) merupakan salah satu aturan kendali tangkap yang telah secara sukses diaplikasikan pada pengelolaan perikanan Jepang sejak 1997 [2], [10], [12], [15]-[17]. FHCR dapat digunakan untuk pengelolaan perikanan spesies tunggal dengan memberikan rujukan ilmiah atas besaran kuota tangkapan setiap tahunnya (jumlah tangkapan yang diperbolehkan/JTB). Rujukan diberikan didasarkan pada kelimpahan stok di tahun sebelumnya. Pada konsep feedback, besarnya kuota tangkap suatu sumber daya ikan (SDI) dikontrol dan disesuaikan dengan kelimpahan stok di tahun sebelumnya yang merupakan representasi dari tren hasil tangkapan di periode waktu sebelumnya [18]. Konsep ini akan mampu memberikan variabilitas hasil tangkapan yang kecil dan stabil pada pengelolaan perikanan [12], [16], [19].

Tujuan penelitian ini adalah untuk memperoleh perbandingan teknis aplikasi feedback HCR dan model surplus produksi Schaefer (1955) pada perikanan multispesies dengan menggunakan perikanan layang di Prigi sebagai contoh aplikasi kasus. Hasil penelitian diharapkan mampu menjadi rujukan untuk aplikasi aturan kendali tangkap pada pengelolaaan perikanan multispecies layang di Indonesia.

\section{METODE}

\section{Sumber data}

Data penelitian ini merupakan data sekunder berupa data hasil tangkapan $(\mathrm{kg})$ dan upaya penangkapan (hari melaut) perikanan layang yang terdiri dari tiga spesies layang yaitu $D$. kuroides, $D$. ruselli, dan $D$. macrosoma yang didaratkan di Pelabuhan Perikanan Nusantara (PPN) Prigi (Gambar 1) dalam pada tahun 2011 - 2020. Jumlah hari melaut dihitung untuk dua alat tangkap yang 
digunakan untuk menangkap tiga spesies layang, yaitu pukat cincin dan payang.

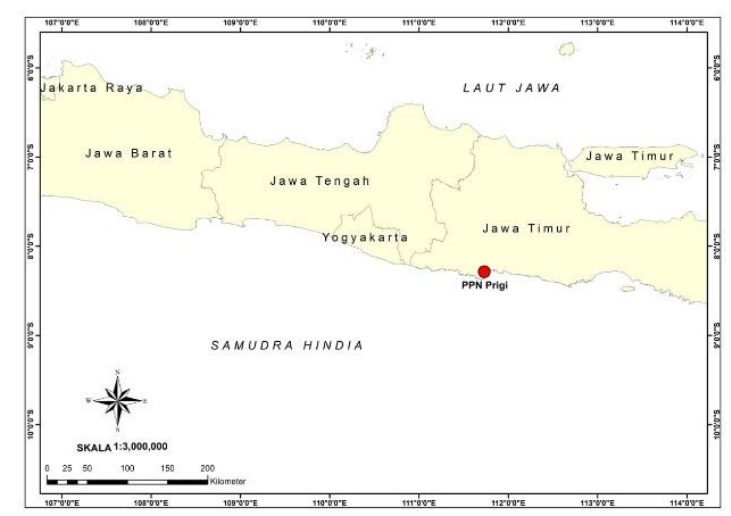

Gambar 1. Peta lokasi penelitian

\section{Analisis Data}

Beberapa analisis data digunakan untuk mengolah data hasil tangkapan dan upaya penangkapan perikanan layang (Decapterus sp) yaitu sebagai berikut:

\section{Hasil tangkapan per unit upaya}

Nilai hasil tangkapan per unit upaya (catch per unit effort/CPUE) menggambarkan indeks kelimpahan stok layang yang dihitung dengan formula [11]:

CPUE $=\frac{c}{f}$

dengan:

CPUE = hasil tangkapan per unit upaya pada tahun $\mathrm{ke}$ - (kg/hari)

$C=$ hasil tangkapan pada tahun ke- $(\mathrm{kg})$

$f \quad=$ upaya penangkapan pada tahun ke(hari)

\section{Aturan kendali tangkap}

Terdapat dua metode yang digunakan untuk memperoleh estimasi jumlah hasil tangkapan yang diperbolehkan (JTB), yaitu dengan menggunakan aplikasi FHCR dan metode surplus produksi yaitu model Schaefer (1954). Kedua metode tersebut diaplikasikan pada data hasil tangkapan tiga spesies SDI layang dan upaya penangkapan yang telah distandarisasi. Perhitungan melalui kedua metode tersebut adalah sebagai berikut:

\section{a. Feedback Harvest Control Rule (FHCR)}

Hasil perhitungan aplikasi FHCR akan memberikan estimasi jumlah tangkapan yang aman secara biologi untuk dimanfaatkan pada tahun ke-y (allowable biological catch/ABCy) [10], [12] dengan menggunakan formula sebagai berikut:

$$
\begin{aligned}
A B C_{y} & =\delta \times C_{y-2} \times \gamma \\
\gamma & =\left(1+k \frac{b}{I}\right)
\end{aligned}
$$

dengan:

$\delta=$ koefisien pembobotan bernilai 1 untuk level stok tinggi dan sedang; dan 0,8 untuk level stok rendah. Level stok diperoleh dari time series indeks kelimpahan stok, dalam hal ini adalah tren hasil tangkapan per unit upaya dalam kurun waktu 2011-2020. Penentuan level tinggi, sedang dan rendah dilakukan dengan mencari nilai batas atas dan batas bawah indeks kelimpahan stok, yang diperoleh dari nilai selisih nilai maksimum dan nilai minimum dengan nilai interval dari hasil tangkapan per unit upaya. Level stok dikatakan tinggi jika nilai hasil tangkapan per unit upaya berada di atas garis batas atas, sedang jika berada di antara garis batas atas dan bawah, dan rendah jika berada di bawah garis batas bawah.

$C_{y-2}=$ hasil tangkapan pada tahun $y-2(\mathrm{~kg})$

$k=$ faktor feedback (bernilai 1)

$\gamma=$ tren CPUE dalam kurun waktu 2011 2020

$b=$ koefisien regresi (slope) CPUE dari tahun $y-4$ hingga $y-2$

$I=$ rata-rata CPUE pada tahun $y-4$ hingga $y-2(\mathrm{~kg} / \mathrm{hari})$

\section{b. Model Schaefer (1954)}

Pada penelitian ini model Schaefer (1954) dipilih sebagai representasi dari model surplus produksi. Model Schaefer bertujuan untuk mengestimasi biomass yang untuk selanjutnya digunakan untuk menentukan tingkat upaya penangkapan yang optimum yang mampu memberikan nilai MSY tanpa berdampak pada produktivitas stok di tahun-tahun mendatang [11]. Model Schaefer (1954) merupakan model surplus produksi yang mendasarkan perhitungan berdasarkan analisis regresi linier antara hasil tangkapan per unit upaya dan upaya penangkapan dengan menggunakan formula sebagai berikut: 


$$
\begin{aligned}
& \frac{c}{f}=a-b f \\
& f_{M S Y}=\frac{a}{2 b} \\
& C_{M S Y}=\frac{a^{2}}{4 b}
\end{aligned}
$$

dengan:

$a \quad=$ intersep

$b \quad=$ koefisien regresi

$f_{M S Y}=$ upaya penangkapan yang akan menghasilkan hasil tangkapan lestari (hari)

$C_{M S Y}=$ hasil tangkapan lestari $(\mathrm{kg})$

\section{HASIL DAN PEMBAHASAN}

Data statistik perikanan layang yang didaratkan di PPN Prigi selama kurun waktu 2011 - 2020 menunjukkan adanya fluktuasi produksi perikanan layang dalam 10 tahun terakhir (Gambar 2). Pada kurun waktu 2011 2014, perikanan layang mengalami penurunan hingga di titik terendah sebesar kurang lebih 5000 ton per tahun di tahun 2014. Penurunan hasil tangkapan tersebut terjadi karena adanya penurunan jumlah alat tangkap yang puncaknya terjadi pada tahun 2014. Sebagai gantinya, terjadi peningkatan kapasitas penangkapan karena sebagian nelayan mengganti alat tangkap payang dan jaring klitik dengan purse seine yang memiliki kapasitas produksi hasil tangkapan lebih tinggi [20]. Hal ini menyebabkan adanya peningkatan produksi di tahun-tahun berikutnya.

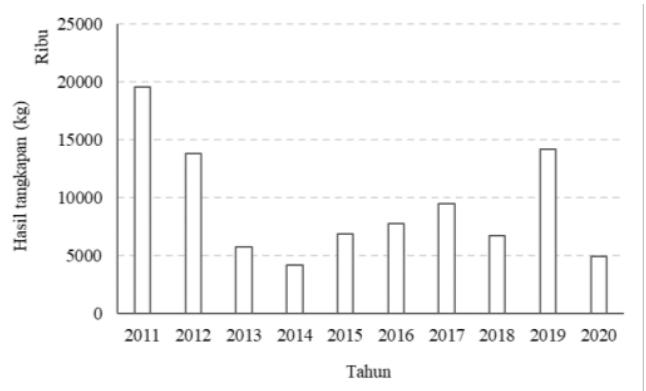

Gambar 2. Produksi perikanan layang 20112020

Berdasarkan hasil tangkapan tiga species layang pada kurun waktu 2011 - 2020 (Gambar 2), perhitungan aturan kendali tangkap diaplikasikan berdasarkan dua pendekatan, dengan metode surplus produksi model Schaefer (1954) dan feedback HCR. Pada pendekatan Schaefer (1954) data hasil tangkapan dan upaya penangkapan dipisahkan berdasarkan 3 spesies layang, sedangkan pada aplikasi feedback HCR data hasil tangkapan dan upaya penangkapan dapat digunakan tanpa dipisahkan berdasarkan species. Secara teknis, aplikasi feedback HCR lebih praktis digunakan karena sumberdaya ikan dianggap sebagai satu unit pengelolaan [2], [12], sehingga dapat dikelola bersama.

Model surplus produksi Schaefer (1954)

Berdasarkan data hasil tangkapan (Gambar 2), estimasi hubungan hasil tangkapan per unit upaya pada kurun waktu 2011 - 2020 dilakukan masing-masing pada 3 species layang. Pada spesies layang anggur $(D$. kuroides) diperoleh hasil regresi linier upaya penangkapan terhadap hasil tangkapan per unit upaya (Gambar 3).

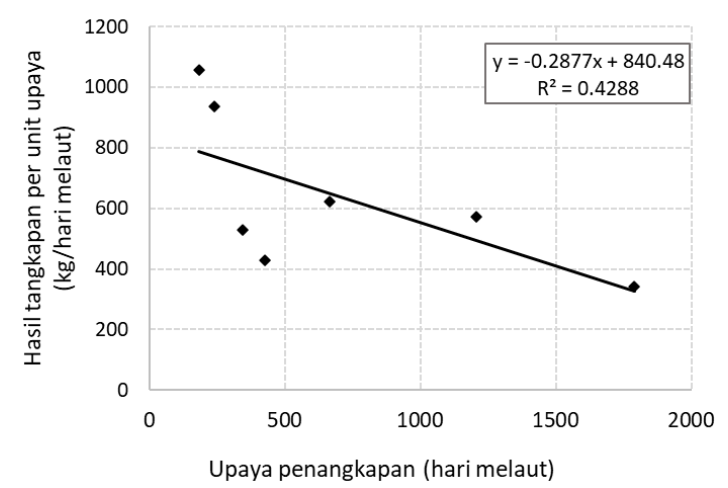

(a)

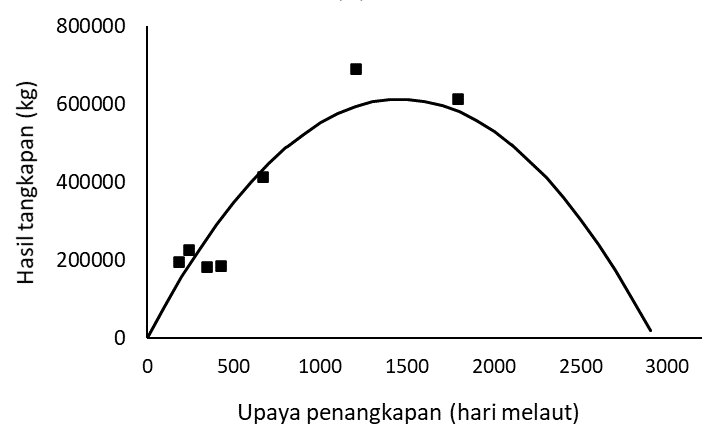

(b)

Gambar 3. Hasil perhitungan dengan menggunakan model surplus produksi Schaefer (1954) (a) Hasil regresi (b) Kurva model produksi pada Decapterus kuroides 
Pada Gambar 3a tampak bahwa hasil regresi menunjukkan kemiringan yang negatif yang mengindikasikan peningkatan jumlah hari melaut akan menyebabkan penurunan jumlah hasil tangkapan $D$. kuroides sebesar $0.28 \mathrm{~kg}$ per hari melaut. Gambar 3b menunjukkan bahwa kurva parabola model produksi Schaefer (1954) menghasilkan estimasi atas nilai potensi lestari (maximum sustainable yield/ $C_{M S Y}$ ) sebesar $613.912 \mathrm{~kg}$. Aturan kendali tangkap yang berlaku di Indonesia, menyatakan bahwa jumlah tangkapan yang diperbolehkan adalah sebesar $80 \%$ dari potensi lestari [21], maka nilai jumlah tangkapan yang diperbolehkan (JTB) atau allowable biological catch $\left(A B C_{y}\right)$ adalah sebesar $491.130 \mathrm{~kg}$, dan nilai allowable biological effort $\left(A B E_{y}\right)$ sebesar 809 hari melaut.

Pada dua species layang lainnya, yaitu layang benggol ( $D$. ruselli) dan layang deles (D. macrosoma), estimasi JTB atau $A B C_{y}$ dengan menggunakan model surplus produksi tidak dapat dilakukan karena tidak memenuhi asumsi model Schaefer (1954). Salah satu asumsi model surplus produksi adalah [22] koefisien regresi antara upaya penangkapan terhadap hasil tangkapan per unit upaya bernilai negatif. Hubungan linier antara dua variabel pada kedua spesies layang yang didaratkan di PPN Prigi menunjukkan hubungan yang positif yang mengindikasikan peningkatan hari melaut akan tetap mampu menyebabkan peningkatan hasil tangkapan per unit upaya. Kondisi semacam ini dinilai sebagai salah satu keterbatasan metode surplus produksi [23] karena estimasi tidak dapat dilakukan pada kondisi perikanan yang sehat, dimana stok belum mencapai potensi lestari.

\section{Aplikasi Feedback HCR}

Berdasarkan perhitungan level stok $(\delta)$ yang diperoleh dari tren stok dalam kurun waktu 2011 - 2020 menunjukkan berada pada level rendah yang bernilai 0,8 (Gambar 4).

Hasil tangkapan tiga spesies layang pada dua tahun sebelum tahun estimasi $\left(C_{2019}\right) 2019$ yaitu sebesar $14.223 .940 \mathrm{~kg}$. Koefisien regresi (b) untuk tren $C P U E_{2017}-2019$ adalah sebesar 59.6, sedangkan rata-rata tren (I) $C P U E_{2017}-$ 2019 adalah $870,9 \mathrm{~kg} /$ hari melaut.

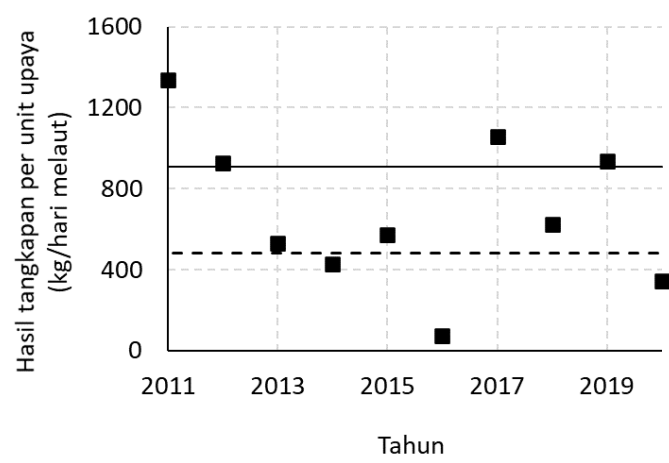

Gambar 4. Level stok Decapterus spp

Dari perhitungan di atas, maka dihasilkan nilai JTB yang aman secara biologi untuk dapat dimanfaatkan $\left(A B C_{2021}\right)$ adalah sebesar $10.599 .675,66 \mathrm{~kg}$ dan besaran upaya penangkapan yang dapat dilakukan pada tahun $2021\left(A B E_{2021}\right)$ adalah sebesar 11.328 hari melaut.

Jika dibandingkan secara teknis dengan metode surplus produksi, aplikasi feedback HCR adalah aplikasi yang praktis karena mampu mengestimasi JTB yang aman secara biologi tanpa melakukan pemisahan data hasil tangkapan dan upaya penangkapan per spesies. Pada aplikasi ini, perhitungan JTB dapat dilakukan tanpa membutuhkan estimasi biomassa stok per spesies/grup spesies. Secara prinsip, penentuan JTB melalui feedback HCR menggunakan tren indeks kelimpahan stok pada beberapa tahun terakhir, yang pada penelitian ini menggunakan tren hasil tangkapan per unit upaya yang terekam pada penentuan level stok. Untuk selanjutnya, kelimpahan stok di tahun-tahun sebelumnya dijadikan dasar untuk menentukan JTB di tahun mendatang sebagai referensi kuota tangkap [10], [12], [16], [17].

Secara umum, hasil penentuan JTB kedua aturan kendali tangkap, baik dengan metode surplus produksi maupun dengan menggunakan feedback HCR diambil dengan prinsip kehati-hatian yang aman secara biologi untuk dapat diaplikasi pada perikanan [24], [25].

Perbedaan yang paling mendasar dari kedua aturan kendali tangkap tersebut adalah pada referensi kelimpahan stok. Pada model Schaefer (1954), diperlukan estimasi biomassa yang didasarkan pada time series data, 
sedangkan pada feedback HCR membutuhkan data kelimpahan stok 4 tahun terakhir untuk mampu memberikan nilai kuota tangkap. Meski demikian, penggunaan feedback HCR tetap mempertimbangkan level stok meskipun dengan proporsi yang tidak sebesar kelimpahan di 4 tahun terakhir [12], [17]. Secara teknis, hasil estimasi nilai kuota tangkap yang dihasilkan oleh feedback HCR mampu meminimalisasi resiko tingginya variabilitas hasil tangkapan karena merupakan hasil adaptasi kelimpahan stok terkini dengan tetap mempertimbangkan tren historis indeks kelimpahan stok (level stok/ $\delta$ ). Perikanan dengan variabilitas hasil tangkapan yang rendah merupakan faktor penting dalam pengelolaan perikanan yang berkelanjutan [26]

Lebih jauh lagi, kondisi perikanan dengan banyak spesies (multispesies) yang beresiko terjadinya agregasi spesies pada pencatatan data perikanan akan jauh lebih praktis jika menggunakan aplikasi feedback HCR. Hal itu dikarenakan, aplikasi ini tetap mampu melakukan estimasi meski dengan data yang tercampur (mixed-species data), sehingga pengguna tidak perlu menyediakan data spesies yang spesifik yang hanya diperoleh dari pemisahan terhadap data hasil tangkapan dan upaya penangkapan berdasarkan spesies [2], [4], [12].

\section{KESIMPULAN}

Secara teknis aplikasi feedback HCR mampu menghasilkan nilai $\mathrm{ABC}_{\mathrm{y}}$ dan $\mathrm{ABE}_{\mathrm{y}}$ untuk spesies dengan data tercampur tanpa harus dilakukan pemisahan data hasil tangkapan dan upaya penangkapan untuk masing-masing spesies. Aplikasi ini tetap mampu mengestimasi nilai $\mathrm{ABC}_{\mathrm{y}}$ dan $\mathrm{ABE}_{\mathrm{y}}$ pada kondisi perikanan yang sehat, dimana peningkatan upaya penangkapan akan menyebabkan peningkatan hasil tangkapan per unit upaya yang tidak mampu dilakukan oleh model Schaefer (1954).

\section{SARAN}

Penggunaan feedback HCR sebagai alternatif aturan kendali tangkap pada perikanan layang di Prigi perlu dipertimbangkan mengingat pentingnya upaya minimalisasi variabilitas hasil tangkapan dalam pengelolaan perikanan layang yang berkelanjutan.

\section{UCAPAN TERIMA KASIH}

Penulis mengucapkan terimakasih kepada mitra bestari yang telah memberikan saran untuk perbaikan naskah ini, kepada pihak Pelabuhan Perikanan Nusantara Prigi, Trenggalek untuk penyediaan data produksi perikanan layang serta kepada Farisa Mardiana Rahma yang telah membantu proses tabulasi data penelitian.

\section{DAFTAR PUSTAKA}

[1] F. H. Wijaya, "Aspek Biologi dan Status Pemanfaatan Ikan Layang (Carangidae-Decapterus) Yang Didaratkan Di Pelabuhan Perikanan Nusantara (PPN) Prigi, Trenggalek." Universitas Brawijaya, 2019.

[2] L. I. Harlyan, T. F. Matsuishi, and M. F. Md Saleh, "Feasibility of a singlespecies quota system for management of the Malaysian multispecies purseseine fishery," Fish. Manag. Ecol., vol. 28, no. 2, pp. 126-137, Jan. 2021, doi: 10.1111/fme. 12470 .

[3] Y. Kato, "Steering the small-scale fisheries of Southeast Asia towards responsible development," Fish for the People. Vol 6. No. 1, Bangkok, Thailand, pp. 3-9, 2008.

[4] S. Yuniarta, P. A. M. van Zwieten, R. A. Groeneveld, S. H. Wisudo, and E. C. van Ierland, "Uncertainty in catch and effort data of small- and medium-scale tuna fisheries in Indonesia: Sources, operational causes and magnitude," Fish. Res., vol. 193, pp. 173-183, Sep. 2017 , doi: 10.1016/j.fishres.2017.04.009.

[5] H. Ilhamdi, R. Telussa, and D. Ernaningsih, "Analisis tingkat pemanfaatan dan musim penangkapan ikan pelagis di Perairan Prigi Jawa Timur," J. Ilm. Satya Mina Bahari, vol. 
1, no. 1, pp. 52-64, 2016.

[6] S. Suwarso, A. Wujdi, and M. Fauzi, "Exploitation and catch fluctuation of small pelagic fishes in prigi waters, south coast of Java," Indones. Fish. Res. J., vol. 20, no. 2, pp. 69-76, 2014.

[7] B. C. R. Sitinjak, "Dinamika Populasi Ikan Layang Deles (Decapterus macrosoma) yang Didaratkan di Instalansi Pelabuhan Perikanan Nusantara Prigi, Kabupaten Trenggalek." Universitas Brawijaya, 2020.

[8] D. P. Ningtyas, "Aspek Biologi Ikan layang biru (Decapterus macarellus Cuvier, 1833) yang Didaratkan di Pelabuhan Perikanan Nusantara (PPN) Prigi Trenggalek Jawa Timur." Universitas Brawijaya, 2019.

[9] M. Karimah, "Dinamika Populasi Ikan Layang Deles (Decapterus macrosoma Bleeker, 1851) yang Didaratkan di Pelabuhan Perikanan Nusantara (PPN) Prigi Kabupaten Trenggalek, Jawa Timur.” Universitas Brawijaya, 2020.

[10] L. I. Harlyan, W. K. Sari, F. M. Rahma, F. Fuad, and M. A. Rahman, "Pengelolaan Sumber Daya Ikan Cakalang didaratkan di Pelabuhan Perikanan Nusantara (PPN) Prigi, Trenggalek: Aplikasi Feedback Harvest Control Rule," Mar. Fish. J. Mar. Fish. Technol. Manag., vol. 11, no. 1, pp. 111-120, 2020, doi: 10.29244/jmf.v11i1.34866.

[11] P. Sparre and S. C. Venema, "Introduction to tropical fish stock assessment. Part 1: manual," Rome, 1992.

[12] L. I. Harlyan, D. Wu, R. Kinashi, M. Kaewnern, and T. Matsuishi, "Validation of a feedback harvest control rule in data-limited conditions for managing multispecies fisheries," Can. J. Fish. Aquat. Sci., vol. 76, no. 10, pp. 1885-1893, May 2019, doi: 10.1139/cjfas-2018-0318.

[13] M. A. Z. Fuad et al., Metode Penelitian Kelautan dan Perikanan. Malang: UB Press, 2020.

[14] L. I. Harlyan, T. Matsuishi, and M. F.
Md Saleh, "Feasibility of a singlespecies quota system for management of the Malaysian multispecies purseseine fishery," Fish. Manag. Ecol., vol. In press, no. 00, pp. 1-12, 2020, doi: 10.1111/fme.12470.

[15] Hiramatsu K., "Evaluation of the ABC decision rule by the operating model approach," Nippon Suisan Gakkaishi, vol. 70, no. 6, pp. 879-883, 2004.

[16] S. Ohshimo and M. Naya, "Management strategy evaluation of fisheries resources in data-poor situations using an operating model based on a production model," Japan Agric. Res. Q. JARQ, vol. 48, no. 2, pp. 237-244, 2014, doi: 10.6090/jarq.48.237.

[17] M. Ichinokawa, H. Okamura, and H. Kurota, "The status of Japanese fisheries relative to fisheries around the world," ICES J. Mar. Sci., vol. 74, no. 5, pp. 1277-1287, May 2017, doi: 10.1093/icesjms/fsx002.

[18] K. G. Magnusson, "A feedback and probing strategy to regulate harvesting from a renewable resource," Math. Med. Biol., vol. 9, pp. 43-65, Jan. 1992, doi: 10.1093/imammb/9.1.43.

[19] E. Hoshino, E. J. Milner-Gulland, and R. M. Hillary, "Bioeconomic adaptive management procedures for short-lived species: A case study of Pacific saury (Cololabis saira) and Japanese common squid (Todarodes pacificus)," Fish. Res., vol. 121-122, no. Supplement C, pp. 17-30, Jun. 2012, doi: 10.1016/j.fishres.2012.01.007.

[20] M. Farikin, H. Boesono, and D. Wijayanto, "Analisis pengembangan fasilitas Pelabuhan Perikanan Nusantara Prigi Kabupaten Trenggalek Jawa Timur ditinjau dari aspek produksi," J. Fish. Resour. Util. Manag. Technol., vol. 4, no. 4, pp. 8796, 2015.

[21] Kementrian Kelautan dan Perikanan, "Keputusan Menteri Kelautan dan Perikanan Republik Indonesia No. 107/KEPMEN-KP/2015," Jakarta, 2015. 
[22] M. J. Alwi, H. Abdullah, and E. Aras, "Status Pemanfaatan Ikan Cakalang (Katsuwonus Pelamis) Di Perairan Kabupaten Luwu Sulawesi Selatan," J. Indones. Trop. Fish. J. Akuakultur, Teknol. Dan Manaj. Perikan. Tangkap, Ilmu Kelaut., vol. 2, no. 2, pp. 216-228, 2019.

[23] J. C. Seijo, O. Defeo, and S. Salas, "Fisheries bioeconomics: theory, modelling and management," AO Fish. Tech. Pap. No. 368, Jan. 1998.

[24] M. Ichinokawa et al., "Searching for optimum management procedures by quantifying management objectives for Japanese domestic fishery stocks without stock biomass estimation,"
Nippon Suisan Gakkaishi, vol. 81, no. 2, pp. 206-218, 2015, doi: 10.2331/suisan.81.206 [In Japanese].

[25] M. W. Pedersen and C. W. Berg, "A stochastic surplus production model in continuous time," Fish Fish., vol. 18, no. 2, pp. 226-243, 2017.

[26] X. He and J. C. Field, "Effects of recruitment variability and fishing history on estimation of stockrecruitment relationships: Two case studies from U.S. West Coast fisheries," Fish. Res., vol. 217, pp. 2134, 2019, doi: https://doi.org/10.1016/j.fishres.2018.0 6.001 . 